\title{
CAUSATION AS A CONDITION FOR LIABILITY FOR BREACH OF CONTRACT UNDER GERMAN CIVIL LAW
}

\author{
Dmitry E. Zakharov \\ Ural State Law University, Yekaterinburg, Russian Federation
}

\begin{abstract}
Introduction: the Civil Code of Germany is of great importance not only as a source of civil law of Germany, but also as a source, which had a great influence on the development of the key institution of civil law - the institution of civil liability, therefore, the author of the work set the goal to investigate causation as a condition of liability for breach of contract under the laws of Germany. Methods: the methodological framework for the study is a set of methods of scientific knowledge, among which the main ones are the methods of system, analysis and comparative law. Results: based on the conducted research, it was found that in Germany, cause-and-effect relationship is one of the elements of the set of facts that serves as the basis for bringing a person to civil liability for violation of the contract; the study shows that the approach to defining the concept and establishing the presence of a causal relationship in Germany is fundamentally different from that adopted in the Russian jurisprudence. Conclusions: based on the theoretical analysis, it is concluded that there are different approaches to determining the cause-and-effect relationship depending on the type of contractual obligation violated and the type of civil liability; a two-step algorithm for recognizing the existence of the causal relationship is established, and the cause of the adverse property consequences of the offense is the behavior of the person not only from the position of a specific situation, which is typical and adequate for any other civil offense.
\end{abstract}

Key words: liability, German Civil Code, breach of contract, cause-and-effect relationship, compensation for damages.

Citation. Zakharov D.E. Causation as a Condition for Liability for Breach of Contract Under German Givil Law. Legal Concept, 2020, vol. 19, no. 1, pp. 132-138. (in Russian). DOI: https://doi.org/10.15688/lc.jvolsu.2020.1.19

УДК 347

ББК 67.404 .2
Дата поступления статьи: 11.01 .2020

Дата принятия статьи: 29.01.2020

\section{ПРИЧИННО-СЛЕДСТВЕННАЯ СВЯЗЬ КАК УСЛОВИЕ НАСТУПЛЕНИЯ ОТВЕТСТВЕННОСТИ ЗА НАРУШЕНИЕ ДОГОВОРА ПО НЕМЕЦКОМУ ГРАЖДАНСКОМУ ПРАВУ \\ Дмитрий Евгеньевич Захаров \\ Уральский государственный юридический университет, г. Екатеринбург, Российская Федерация \\ Введение: гражданское Уложение Германии имеет большое значение не только как источник граждан- ского права ФРГ, но и как источник, оказавший большое влияние на развитие важнейшего института граж-}


данского права - института гражданско-правовой ответственности, в связи с чем автором в работе поставлена цель: исследование причинно-следственной связи как условия ответственности за нарушение договора по законодательству Германии. Метод: методологическую основу данного исследования составляет совокупность методов научного познания, среди которых основное место занимают методы системности, анализа и сравнительно-правовой. Результаты: на основании проведенного исследования установлено, что в Германии причинно-следственная связь является одним из элементов юридического состава, выступающим основанием привлечения лица к гражданско-правовой ответственности за нарушение договора; проведенное исследование показывает, что подход к определению понятия и установлению наличия причинной связи в Германии принципиальным образом отличается от того, что принят в российской юриспруденции. Выводы: на основе теоретического анализа делается вывод о разных подходах к определению причинно-следственной связи в зависимости от вида нарушаемой договорной обязанности и вида гражданско-правовой ответственности; установлен двухступенчатый алгоритм признания существования причинной связи, и причиной наступивших неблагоприятных имущественных последствий правонарушения является поведение лица не только с позиции конкретной ситуации, а типично и адекватно для любого иного гражданского правонарушения.

Ключевые слова: ответственность, гражданское Уложение Германии, нарушение договора, причинно-следственная связь, возмещение убытков.

Цитирование. Захаров Д. Е. Причинно-следственная связь как условие наступления ответственности за нарушение договора по немецкому гражданскому праву // Legal Concept = Правовая парадигма. - 2020. T. 19, № 1. -C. 132-138. -DOI: https://doi.org/10.15688/lc.jvolsu.2020.1.19

\section{Введение}

Вопрос о значении и сущности условий привлечения к гражданско-правовой ответственности не нов, и имеет богатую правовую историю. Рассмотрение указанного вопроса было предметом исследования как дореволюционных цивилистов, так и ученных советского периода, не потеряла актуальности эта проблема и на страницах современной юридической литературы. Нельзя не отметить, что в настоящее время лишь единичные исследования посвящены теоретическому осмыслению условий ответственности за нарушение договора по немецкому гражданскому праву, что объясняется сложностью юридического перевода соответствующей литературы и затруднительностью ее получения.

Гражданское Уложение Германии выступает в качестве одного из старейших нормативно-правовых актов, ставшим источником гражданского права для многих стран романогерманской правовой семьи. Гражданско-правовая ответственность возлагается на должника в случае установления причинной связи между его поведением и возникшими негативными последствиями на стороне потерпевшего. При этом установление наличия такой связи не формальная необходимость или сугубо теоретическая конструкция, а прямое требование немецкого гражданского Уложения.

\section{Причинно-следственная связь как элемент юридического состава}

При рассмотрении вопроса о предпосылках возникновения гражданско-правовой ответственности нельзя обойти вопрос о юридическом составе гражданского правонарушения. Следует отметить, что общий юридический состав нарушения договора, как и в большинстве европейских правопорядках, немецкому праву был не известен, что было скорректировано в ходе проведения реформы обязательственного права $[10$, S. 1]. Традиционным для немецкой юриспруденции является конструкция юридического состава (Tatbestand), среди которого различают состав ответственности (Haftungstatbestand), и в связи с проведением реформы в современной юриспруденции принято выделять также и юридический состав нарушения обязанности (Pflichtverletzungstatbestand), соединивший в себе различные случаи нарушения обязательства (просрочка, ненадлежащее исполнение, неисполнение). Общепризнанная конструкция юридического состава гражданско-правовой ответственности имеет трехзвенную структуру, в которую входит так называемый объективный состав (objektiver Tatbestand), элементами которого выступают факторы и процессы, не зависящие от воли и желания лица, к ним относятся поведение, нарушающее дого- 
ворную обязанность, ущерб и причинно-следственная связь между первым и вторым. Отдельным компонентом состава ответственности выступает противоправность. Венчает конструкцию состава субъективный состав (subjektiver Tatbestand), включающий долженствование ответить и вину.

Необходимость наличия причинно-следственной связи между нарушением договора и возникшими убытками явствует из содержания § 280 Гражданского Уложения Германии (далее - ГГУ), устанавливающего, что если должник нарушит свою обязанность, вытекающую из обязательства, то кредитор вправе требовать возмещения вызванного этим ущерба. Согласно теоретическим представлениям немецких ученых связь между поступком, нарушающим обязанность, и наступившими негативными имущественными последствиями имеет три уровня: внешний фактор, порождающий взаимообусловленность поведения и вреда; правовая оценка (rechtlichen Bewertung) поведения лица, чьим действием или бездействием вызвано наступление убытков; взаимосвязь ответственности виновника за убытки в субъективном смысле (вина и необходимость отвечать) [11, S. 249]. Важно подчеркнуть, что в немецкой науке различаются теоретические подходы к определению сущности причинно-следственной связи при нарушении обязательства и причинении вреда. В последнем случае за основу принимается теория «эквивалентной каузальности», формула которой сводится к тому обстоятельству, что любое условие выступает причиной для какого-либо явления, если не представляется возможным помыслить отсутствие этого условия без того, чтобы вместе с тем и отпал и сам результат такого условия [4, с. 136].

Согласно основам немецкой юриспруденции установление причинно-следственной связи при нарушении договора происходит поэтапно, на каждом из которых правоприменитель проводит проверку обоснованности привлечения лица к ответственности. На первой стадии устанавливается наличие причинно-следственной связи, «обосновывающей» применение ответственности (haftungsbegründenden Kausalität). Функциональное значение рассматриваемого этапа - это выявление наличия условия привлечения к ответственности, которое заключается в установлении причастности правонарушителя к совершенному деянию для последующего возложения на него обязанности возместить причиненные убытки. Следующий этап проверки связан с выявлением наличия причинно-следственной связи, «наполняющей» ответственность (haftungsausfüllende Kausalität). Проведение этого звена проверки позволяет ответить на вопрос «какова же ответственность?» и при этом определить размер убытков, подлежащих возмещению [7, S. 222]. На первом этапе устанавливается наличие связи между поведением правонарушителя и нарушением обязанностей, на втором этапе обнаруживается юридическая сцепка между нарушением обязанностей и наступившими убытками [8, S. 358].

Дальнейшее установление причинноследственной связи зависит от вида нарушенной обязанности, возникшей на основании заключения договора. Согласно теоретическим основам немецкой науки гражданского права основной обязанностью должника выступает обязанность предоставления (Leistungspflicht) кредитору обещанного посредством заключения с ним договора. В состав обязательства наряду с обязанностью по его исполнению включаются охранительные обязанности (Schutzpflichten) учитывать права, блага и интересы контрагента по договору. Обязанность по предоставлению отражает сущность возникшего договорного обязательства и ее исполнение обусловлено предметом договора (передать товар, выполнить работу, оказать услугу). Соблюдение охранительных обязанностей предотвращает причинение вреда имуществу и здоровью контрагентов при исполнении заключенного ими договора. Нарушение как обязанности по предоставлению, так и охранительной обязанности влечет привлечение лица к ответственности за нарушение договора. Нарушение таких разных по своей природе договорных обязанностей не могло не обусловить различные подходы к установлению причинно-следственной связи.

Применительно к нарушению обязательств по предоставлению вполне достаточно установить наличие причинно-следственной связи между обосновывающим ответственность поведением и подлежащими возмещению убытками, поскольку нарушение 
договорной обязанности напрямую вызывает ответственность, а при несоблюдении охранительной обязанности требуется установить связь не только между поведением и нарушением такой обязанности, но и определить, что убытки явились следствием такого нарушения [6, S. 198-199].

\section{Теория адекватного причинения и иные концепции, определения взаимообусловленности поведения и причиненных убытков}

Верховный Суд Германии определил причинно-следственную связь как «нить» между поведением и результатом, достигнутым в ходе поведения лица, «отвечающим реальному положению вещей, а не только особым и необычным обстоятельствам, которые разумный человек в повседневной жизни не принимает во внимание» [3, с. 364]. Соответственно Верховный Суд Германии указал, что именно в условиях обычного (повседневного) течения жизни возникает обстоятельство, приводящее к результату, квалифицируемому как следствие правонарушения; и именно обычный ход вещей (при котором возникает нарушение договора) влечет правовой результат (причинение убытков). Такой подход исходит из причинно-следственной связи между обычным, повседневным течением жизненных обстоятельств, наступление которых и приводит к результату, рассматриваемому правом в качестве одного из элементов состава правонарушения.

Представление о причинно-следственной связи как явлении реальной действительности, связывающей между собой событие и результат, обычно наступающий в таком случае, получило в науке немецкого гражданского права наименование «теория адекватной причинной связи» (Adäquanztheorie). Применение указанной теории предполагает некую искусственную абстракцию и анализ причинно-следственной связи через взгляд «опытного и искушенного наблюдателя», для которого поведение субъекта и наступившие последствия обычным образом сообразуются между собой и не являются чем-то необыкновенным и немыслимым. Рассмотренный прием установления причинно-следственной связи является сугубо теоретической конструкцией и не имеет своего законодательного закрепления, что не мешает судьям использовать его при вынесении судебных актов. Согласно положениям теории сторона договора освобождается от ответственности, если нарушение договора и как следствие наступление убытков явилось результатом поведения стороннего лица или наступления событий, нарушающих обычный ход вещей. При этом применение теории «адекватной причинной связи» может привести к ограничению размера взыскиваемых убытков, если суметь доказать, что «нарушение договора не повысило в значительной мере объективную возможность возникновения ущерба, который причинен в действительности» $[1$, с. 44].

Рассматривая вопрос об установлении связи между правонарушением и его последствиями, нельзя не упомянуть учение о целях защиты (Schutzzwecklehre), на основании которого правоприменитель определяет убытки, подлежащие возмещению в пользу потерпевшего. В основу этого учения положена идея, что цель норм об ответственности состоит в необходимости обеспечить защиту конкретных интересов, а возникновение, осуществление, прекращение договорных обязанностей должно соответствовать цели заключения договора, и тем самым санкции за нарушение договорных обязанностей должны соответствовать таким целям [9, S. 101]. Рассматриваемое учение призвано обеспечить защиту интересов кредитора посредством ответственности, наступающей за те негативные последствия, которые не противоречат целям заключенного договора. Отказ в защите интересов и как следствие отказ в возмещении соответствующих убытков обусловлены защитной функцией правовой нормы (Schutzweckder Norm), устанавливаемой на основе телеологического толкования закона. Возмещению подлежат именно те потери, наступление которых попадает в сферу охраны правовой нормы и, как отмечают немецкие цивилисты, применение рассматриваемой теории означает возложение обязанности по возмещению исключительно того вреда, который по виду и способу причинения охватывается охранительной целью нарушенной нормы и, соответственно, возмещению подлежит 


\section{МЕЖДУНАРОДНОЕ ПРАВО И СРАВНИТЕЛЬНОЕ ПРАВОВЕДЕНИЕ}

ущерб, восходящий к опасности, для предотвращения которой принята нарушенная норма или нарушенная договорная, или преддоговорная обязанность [2, с. 244].

Если для теории адекватной причинноследственной связи не имеет значение цель правовых норм об ответственности и главенствующим является абстрактная оценка вероятности (Wahrscheinlichkeitsurteil), то учение о целях защиты, напротив, ориентируется на основание и условия ответственности, а также смысл и значение правовых установлений законодателя [9, S. 101]. Немецкими юристами в обязательственном праве учение о цели защиты рассматривается как средство ограничения ответственности не с целью ущемления прав кредитора при возмещении ему убытков, а с целью оптимального и справедливого определения размера и вида убытков, подлежащих возмещению. Как подчеркивают юристы, применение учения о защитной функции ведет к сокращению объема ответственности, но при этом и фиксируются негативные последствия, которые не могли быть предвидимы и как следствие от которых нельзя было бы застраховаться, как, например, при заключении договора о медицинском вмешательстве, который таит в себе в случае его нарушения неисчислимые и безграничные риски для должника [6, S. 399-400]. Для решения правоприменителем вопроса о возмещении убытков ему необходимо определить интересы кредитора исходя из видовой принадлежности договора и специфики его содержания, проследив влияние нарушения договора и дезорганизацию интересов кредитора, связанных с заключением и исполнением нарушенного договора. Примерами применения учения о защитной функции служит решение суда, согласно которому неисправность весов привела к заниженной цене товара, но суд посчитал, что корректное установление физических параметров вещи не затрагивает защитного действия заключенного договора. В другом деле застрахованный груз транспортировался на другом судне, чем это было предусмотрено договором и впоследствии при шторме погибло судно, на котором предполагалось осуществлять перевозку, а иное судно не пострадало и груз получил незначительные повреждения. Несмотря на то обстоятель- ство, что было нарушение договора, суд отказал в требовании о возмещении убытков, поскольку защитная функция заключенного договора не касалась неисполнения договора и требования страховой суммы, а относилась к безопасности транспортировки груза [6, S. 399-400].

При возмещении убытков причинноследственная связь обеспечивает принцип «полной репарации» (Total reparation), согласно которому потерпевшее лицо вправе требовать от правонарушителя того, чтобы положение первого было таковым, как если бы негативные последствия в имущественной и личной сфере пострадавшего вовсе не случились. Лицо, обладающее правом на возмещение убытков, вправе потребовать, чтобы ему была обеспечена компенсация за все имущественные потери, находящиеся в адекватной причинно-следственной связи с явлением, вызвавшим ущерб [5, с. 102].

\section{Выводы}

Следует признать, что в немецком гражданском праве причинно-следственная связь входит в состав юридической конструкции состава правонарушения и установление наличия причинно-следственной связи выступает одним из условий привлечения к ответственности за нарушение договора. Концепция «адекватной причинно-следственной связи», являясь результатом теоретических разработок немецких цивилистов, широко применяется правоприменителем при разрешении споров, связанных с нарушением договора.

Причинно-следственная связь в немецком гражданском праве носит объективный характер и является реально существующей, что исключает субъективный подход к ее определению. Адекватная причинно-следственная связь исключает косвенную взаимообусловленность причины и следствия и исходит исключительно из прямой зависимости нарушения договора и причиненных убытков. Методика установления причинно-следственной связи различается при ответственности за нарушение договора и причинение вреда. Адекватная связь определяет наступление одного явления в результате другого, выступая типичным (обычным) для такой причин- 
но-следственной связанности. Применение теории «адекватного причинения» позволяет правоприменителю не только установить причинно-следственную связь, но и исключить взыскание сверхкомпенсационных убытков, тем самым ограничив ответственность должника в пределах, очевидных для любого участника оборота.

\section{СПИСОК ЛИТЕРАТУРЫ}

1. Комаров, А. С. Ответственность в коммерческом обороте / А. С. Комаров. - М. : Юрид. лит., 1991. $-208 \mathrm{c}$.

2. Сераков, В. В. Теория адекватной причинности как способ ограничения размера причиненных убытков / В. В. Сераков // Вестник гражданского права. - 2014. - Т. 14, № 5. - С. 233-252.

3. Цвайгерт, К. Введение в сравнительное правоведение в сфере частного права: Договор, неосновательное обогащение. Деликт / К. Цвайгерт, Х. Кетц. - М. : Междунар. отношения, 2000. T. 2. $-512 \mathrm{c}$.

4. Шапп, Я. Система германского гражданского права / Я. Шапп ; пер. с нем. С. В. Королева. М. : Междунар. отношения, 2006. -360 с.

5. Штоль, Х. Ответственность и ее границы в рамках договоров в области экономических отношений между СССР и ФРГ / Х. Штоль // СССР ФРГ: договор во внугренних и двусторонних хозяйственных отношениях / редкол.: М. М. Богуславский, В. В. Лаптев, А. А. Рубанов. - М. : ИГПАН, 1986. - C. 92-110.

6. Brieskorn, K. Vertragshaftung und responsabilite contractuelle. Ein Vergleich zwischen deutschem und französischem Recht mit Blick auf das Vertragsrecht in Europa / B. Konstanze. - Tübingen : Mohr Siebeck Verlag, 2010. - 488 S.

7. Esser, J. Schuldrecht. Band I Allgemeiner Teil: Teilband 1. Entstehung, Inhalt und Beendigung von Schuldverhältnissen. Ein Lehrbuch. 8 Auflagen / J. Esser, E. Schmidt.-Heidelberg: C.F. Müller Verlag, 1995. - 355 S.

8. Fuchs, M. Delikts- und Schadenersatzrecht. 8., aktualisierte und erweitere Auflage / M. Fuchs, W. Pauker. - Berlin ; Heidelberg : Springer; Verlag, 2012. $-416 \mathrm{~S}$.

9. Lange, H. Handbuch des Schuldrechts: Schadenersatz / H. Lange, G. Schiemann. - Band 1. 3 Auflage, Tübingen : Mohr Siebeck Verlag, 2003.$826 \mathrm{~S}$.

10. Mitzkait, A. Leistungsstörung und Heftungsbefreiung: Ein Vergleich der Grundregeln des Europäischen Vertragsrechts mit dem reformierten deutschen Recht / A. Mitzkait. - Tübingen : Mohr Siebeck Verlag, 2008. - 293 S.
11. Wolfgang Fikentscher. Schuldrecht. - Berlin : Walter De Gruyter Verlag, 1965. - 712 S.

\section{REFERENCES}

1. Komarov A.S. Otvetstvennost $v$ kommercheskom oborote [Responsibility in Commercial Turnover]. Moscow, 1991.208 p.

2. Serakov V.V. Teoriya adekvatnoy prichinnosti kak sposob ogranicheniya razmera prichinennykh ubytkov [Adequate Causality Theory as a Way to Limit the Amount of Damages Caused]. Vestnik grazhdanskogo prava [Bulletin of Civil Law], 2014, vol. 14 , no. 5, pp. 233-252.

3. Tsvaygert K., Ketts Kh. Vvedeniye $v$ sravnitelnoye pravovedeniye $v$ sfere chastnogo prava: Dogovor. neosnovatelnoye obogashcheniye. Delikt [Introduction to Comparative Law in the Field of Private Law: In 2 vols. Volume 2. Translation from German]. Moscow, Mezhdunarodnye otnosheniya, 1998. $512 \mathrm{p}$.

4. Shapp Ya., Koroleva S.V., ed. Sistema germanskogo grazhdanskogo prava [The System of German Civil Law: a Textbook, Translation from German]. Moscow, Mezhdunarodnye otnosheniya, 2006.360 p.

5. Shtol Kh. Otvetstvennost i eye granitsy v ramkakh dogovorov $\mathrm{v}$ oblasti ekonomicheskikh otnosheniy mezhdu SSSR i FRG [Responsibility and Its Borders in the Framework of Agreements in the Field of Economic Relations Between the USSR and Germany]. SSSR - FRG: dogovor vo vnutrennikh i dvustoronnikh khozyaystvennykh otnosheniyakh [USSR - FRG: A Contract in Internal and Bilateral Economic Relations]. Moscow, IGPAN, 1986, pp. 92-110.

6. Brieskorn K. Vertragshaftung und responsabilite contractuelle. Ein Vergleich zwischen deutschem und franzosischem Recht mit Blick auf das Vertragsrecht in Europa [Contractual Liability and Responsabilite Contractuelle. A Comparison Between German and French Law With Regard to Contract Law in Europe]. Tubingen, Mohr Siebeck Verlag, 2010. $488 \mathrm{p}$.

7. Esser J., Schmidt E. Schuldrecht. Band I Allgemeiner Teil: Teilband 1. Entstehung, Inhalt und Beendigung von Schuldverhältnissen. Ein Lehrbuch. 8 Auflagen [Law of Obligations. Volume I. General Part. Origin, Content, and Termination of Obligations. Textbook. 8. Edition]. Heidelberg, C.F. Muller Verlag, $1995.355 \mathrm{p}$.

8. Fuchs M., Pauker W. Delikts und Schadenersatzrecht. 8., aktualisierte und erweitere Auflage [Torts and Damages. 8., Updated and Corrected Edition]. Berlin, Heidelberg, Springer Verlag, 2012. $416 \mathrm{p}$. 


\section{МЕЖДУНАРОДНОЕ ПРАВО И СРАВНИТЕЛЬНОЕ ПРАВОВЕДЕНИЕ}

9. Lange H., Schiemann G. Handbuch des Schuldrechts: Schadenersatz, Band 1. 3 Auflage [Textbook on the Law of Obligations: Compensation for Damages]. Tubingen, Mohr Siebeck Verlag, 2003, vol. 1,3 ed. $826 \mathrm{p}$.

10. Mitzkait A. Leistungsstorung und Heftungsbefreiung: Ein Vergleich der Grundregeln des Europaischen Vertragsrechts mit dem reformierten deutschen Recht [Outsourcing and Exemption from Stemming: A Comparison of the Principles of European Contract Law With the Reformed German Law]. Tubingen, Mohr Siebeck Verlag, 2008. $293 \mathrm{p}$.

11. Wolfgang Fikentscher. Schuldrecht [Law of Obligations]. Berlin, Walter De Gruyter Verlag, $1965.712 \mathrm{p}$.

\section{Information About the Author}

Dmitry E. Zakharov, Candidate of Sciences (Jurisprudence), Associate Professor, Department of Civil Law, Ural State Law University, Grazhdanskaya St., 2a-72, 620107 Yekaterinburg, Russian Federation, zakhaROVZDE@mail.ru,https://orcid.org/0000-0003-1384-5187

\section{Информация об авторе}

Дмитрий Евгеньевич Захаров, кандидат юридических наук, доцент кафедры гражданского права, Уральский государственный юридический университет, ул. Гражданская, 2a-72, 620107 г. Екатеринбург, Российская Федерация, zakhaROVZDE@mail.ru, https://orcid.org/0000-0003-1384-5187 